\title{
Substance, Causality, and Freedom - An Ontological Revision of the Theory of Agent Causation
}

\author{
PEDRo SCHMECHTIG, DRESDEN
}

\section{Introduction}

Libertarian conceptions of free will are discussed on the basis of three different approaches: (a) non-causal theories (Ginet 1990, McCann 1998) assume that a mental or bodily action $\mathrm{H}$ is free when $\mathrm{H}$ was not caused; (b) indeterminist-causal theories (Mele 1995, Ekstrom 2000) consider a bodily action $\mathrm{H}$ as free when $\mathrm{H}$ was produced by the mental processes of the agent in an indeterminist manner; (c) and finally, according to agent causation theories (Chisholm 1985, Taylor 1966) a mental and bodily action $\mathrm{H}$ is free when $\mathrm{H}$ was caused by the agent himself.

From an ontological point of view, all approaches falling under (c) represent a special challenge, since they are based on strong metaphysical assumptions regarding how the relationship between causality and freedom should be perceived. On the one hand, they share the notion with the collective suggestions under (a) that free actions cannot be reduced to one of the different variants of event causality (regularity thesis, counterfactual or probabilistic analyses, transfer theories). On the other hand, they are similar to the approaches that fall under (b) - compatible with the notion that actions are the causal products of the motivational conditions of a person. Nevertheless, they cast doubts on the fact that this alone can be the basis for explaining where the libertarian thought of a free will exists.

Proponents of agent causation assume that persons who have special abilities act differently in order to make decisions. Therefore, a type of substance causation which emphasizes the intervening character is the focus here. Three basic ontological assumptions constitute the basis of this aspect: (i) agents are substantial particulars; (ii) substantial particulars are three-dimensional objects that exist in time according to the traditional endurance-persistence model; and (iii) agents are causes that are not caused ${ }^{1}$

\footnotetext{
${ }^{1}$ Accordingly, one hopes to avoid the general basic problem of libertarianism, that free actions are neither determined through complete causation, nor brought about purely
} 
(i.e., they are the origin and the last source of their decisions because they are only able to intervene in the natural process of things by means of causal hypotheses).

While this approach originally implied a strict separation between event and agent causation, subsequently ${ }^{2}-$ in response to various objections ${ }^{3}-$ there has been some backing away from this assumption. The starting point is the realization that it is not necessary to believe that event and agent causation are mutually exclusive. ${ }^{4}$ Basically, this requires overcoming the traditional notion that there is always a causal determinant involved in the causation of a free act. If one considers the production of an act as a complex co-determined event that results from the simultaneous fusion of two separate causal chains (double causation), then the alleged disconnection appears to be invalid. According to a moderate reading of agent causation both forms of the causality are compatible with one another, as soon as one understands the cause for the event as indeterminist - similar to the theories given under $(b)$.

In the following, I will first sketch the main objection that has spearheaded the opposition to the original version of agent causation. Then, I present arguments for the case that in a moderate reading this difficulty can be resolved; but unfortunately, only at the cost of another problem. Proponents of agent causation have always assumed that the classic luck objection - i.e., an agent cannot be free as long as his action has a purely random cause - can be invalidated with the concept of substance causation. This assumption, however, is countered by the new, moderate reading. Accordingly, this gives rise to the following dilemma: if one accepts the moderate reading, then the concept of substance causation cannot be used as a means for resolving the objection to random actions. If one remains instead with the original perception that motivated the moderate reading, then the problem appears to be one that cannot be resolved. In the final section I try to indicate a path with which one can overcome this dilemma. However, in the process it should become clear that it is not the original understanding

coincidentally on the basis of random factors. This is so since, in both cases, any action on the part of the agent would detract from his active control.

${ }^{2}$ See Taylor $(1966,262)$.

${ }^{3}$ For discussion of this objection, see Aune (1977), Ginet (1990), Keil ( 2000) van Inwagen (2002).

${ }^{4}$ The following are also among the approaches that, in recent times, in one form or another, have pleaded for a compatibility of event and agent causation: Alvarez/Hyman (1998), Chisholm (1995), Clarke (1996; 2003), Markosian (1999), von Wachter (2003). 
of causality that needs revision; much more than that - in order to arrive at a successful defense of agent causation - basic ontological assumptions must be modified. Only under the assumption of a four-dimensional agent causation - this is the central claim - can the dilemma mentioned above be resolved.

2. The Problem of Temporal Causation and the Approach of an EventIntegrated Agent Causation

The plausibility of agent causation, based on substantial individual entities, was already questioned at an early stage with an objection by C. D. Broad (1952):

"I see no prima facie objection to there being events that are not completely determined. But, insofar as an event is determined, an essential factor in its total causes must be other events. How can an event possibly be determined to happen at a certain date if its total cause contained no factor to which the notion of date has any application? And how can the notion of date have any application to anything that is not an event?" (Broad 1952, 215 - my italics).

Since then the missing association of a date serves as the main argument against the approach of agent causation. ${ }^{5}$ This may make one wonder what Broad's objection is all about. First of all, let's consider the following clarification: ${ }^{6}$

\section{The Causal Argument:}

(P1) If an event $\mathrm{E}$ is caused at time $\mathrm{t}$, there has to be a cause $\mathrm{C}$ such that: (i) $\mathrm{C}$ is different from $\mathrm{E}$; (ii) $\mathrm{C}$ occurs at a certain time, and (iii) $\mathrm{C}$ causes that $\mathrm{E}$ occurs at $\mathrm{t}$.

(P2) Requirement (P1) is only fulfilled by entities that themselves occur at a certain time.

(P3) Events are entities that occur at a certain time.

\footnotetext{
${ }^{5}$ Even though, naturally, there are further considerations that speak against agent causation, Keil (200, 364 and 382) for instance alleges that the present 'objection to association of a date' is already sufficient to rebuff this approach. Based on this, Broad's argument represents a 'irresolvable problem' that particularly concerns substance causality, since the 'false' manner of existence of persons and entities is principally not suited to explain the temporal occurrence of causal relations.

${ }^{6}$ Compare: Clarke (2003, 197ff.).
} 
(P4) Agents are entities that do not occur at a certain time because the continuously exist in time.

Therefore:

(K) Agents cannot be the causes of events.

Even though this argument is formally valid, two objections can be made: (i) it is not always the case that events occur at a certain time. Let's think about an event such as the 'Thirty Year War' that took place for many years, or an episode-like event such as tidal changes and sunrises. In view of such types of events, premise (P3) needs an explanation. (ii) Moreover, even though agents exist continuously in time, they can exist at a certain time in which they themselves are the cause of an event. Based on the fact that the agents within an interval of time - e.g. from $t_{1}$ to $t_{3}$ - have the same causal ability, it cannot be deduced that the causing action did not take place directly at $t_{1}, t_{2}$ or $t_{3}$. This problem could be easily resolved by means of temporal indices. However, not only are the premises (P3) and (P4) of the above argument too strong; the entire objection seems to assume what actually must be shown. It already contains the ontological judgment that substantial particulars persist in a way that rules out the possibility of causal effects being compatible with temporal association.

Does this mean that Broad's objection is totally redundant? Not entirely. Even if Broad's objection as a causal argument contains a hidden petito principii, he is possibly correct in another way:

\section{The Explanatory Argument:}

$\left(\mathrm{P} 1^{*}\right)$ If an event $\mathrm{E}$ is caused at time $\mathrm{t}$, there has to be a cause $\mathrm{C}$ such that: (i) $\mathrm{C}$ is different from $\mathrm{E}$; (ii) $\mathrm{C}$ occurs at a certain time, and (iii) $\mathrm{C}$ or parts of $C$ explain why E occurs at time t.

$(\mathrm{P} 2 *)$ Subordinate requirement $[(\mathrm{P} 1 *)$ (iii)] is not fulfilled by entities that themselves exist continuously in time.

$\left(\mathrm{P} 3^{*}\right)$ Events are entities that do not exist continuously in time.

$(\mathrm{P} 4 *)$ Agents are entities that always exist continuously in time.

Therefore:

$\left(\mathrm{K}^{*}\right)$ Agents cannot be the causes of events. 
The decisive modification applies to the sub-condition [P1* (iii)]. Why should we consider premise $(\mathrm{P} 2 *)$ to be more appropriate than $(\mathrm{P} 2)$ in the causal argument based on this condition? Is there something more in favor of $(\mathrm{P} 2 *)$ ? I think that if one takes the following thought into consideration, then one can really find a reason: Let us assume that an agent $\mathrm{S}$ exists during the time interval from $t_{1}$ to $t_{3}$, whereby his action $H$ at $t_{3}$ is the direct cause for a certain event $\mathrm{E}$ - e.g. the occurrence of an explosion. If one asks, why $S$ has caused the explosion at $t_{3}$ and not at $t_{1}$, then the fact that $S$ existed at $t_{3}$ with the corresponding causal ability does not appear to be a satisfactory explanation. Then, the same applies to the point of time $t_{1}$ and $\mathrm{t}_{2}$ equally. What we need is a contrasting explanation that tells us how one can differentiate between cases where the explosion did not occur, but the same agent existed. The mere reference to the agent's causal ability does not help here. One can possibly explain the occurrence of $\mathrm{H}$ at $\mathrm{t}_{3}$. But this explanation is not contrasting. For this purpose an additional reason would have to be provided that makes it clear why such a cause did not occur at the point of time $t_{1}$ and $t_{2}$ respectively. The agent's absence, in any case, cannot be offered as an explanation. In other words (P2*) is better justified since it does not generally deal with the date and time of the substance causation, but with the explanation that the reference to the causal ability has in comparison to other situations - in which the agent also existed but was not the cause of the concerned event.

Let us summarize: Broad's objection is not very convincing in the form of a causal argument; but that does not mean that the objection aimed at a date and time is meaningless. As the modified variants of the original arguments show there is at least an explanatory shortcoming in the context of agent causation: reference to the agent as a cause for his action may include a certain time, but it does not furnish a contrasting explanation why one and the same agent under similar conditions - but at a different time did not produce such an action.

Based on the background presented it makes sense to assume that the concept of agent causation is - in contrast to that which has been claimed so far - compatible with causation through events. In this case, the standard objection can easily be countered:

"In contrast, on an integrated agent-causal account, a free action is caused by the agent (a substance) and by certain agent-involving events, such as the agent's having certain reasons and certain intention. Given such a view, when an agent directly causes an event, part of the total cause of that effect is an event - a date en- 
tity, something that occurs at time, something the occurrence of which at a time may explain why the effect occurs when it does." (Clarke 2003, 198)

If causation represents a free action of a complex co-determined event, two important matters can be connected to one another: (i) the agent himself is the cause and source of the total event brought about (the actual execution of $\mathrm{H}$ ); (ii) in the process of bringing about the event there is an additional event involved that can be associated with a date and time as a part of the total cause. Seen in this manner, every reference to the agent is a contrasting explanation. Then, in addition to the causal ability - that an agent has as a substance - there is a special event that based on its date and time explains why the agent performed his action at $t_{3}$ and not at any other time. The contrasting event consists in the agent having had a reason or the intention to actually perform the action $\mathrm{H}$ only at $\mathrm{t}_{3}$. In other words, the agent himself plus the integrated event of the 'having' in the process of the causation yield a causal explanation that is adequately significant.

Thus the approach to event-integrated agent-causation appears to have the necessary resources to be able to counter the accusation of the missing date and time factor. Despite this, I will make it clear in the next section that an event-integrated approach must strive to be able to keep the problem of the contrasting explanation under control. Generally, it would be questioned if the regress to an indeterminist understanding of event causality is the most appropriate way to protect the incompatible intuitions that are connected with a libertarian concept of the freedom of action and decision.

\section{Causal Explanation and Indeterminist Control}

Broad's causal argument gets settled as soon as one moves away from the claim that it is impossible for events to be an integral component of agent causation. Does this also apply to the objection of the contrasting explanation? Does the mere reference to the agent in the context of the moderate reading furnish a significant explanation? An answer to this question mostly depends on what one understands by a causal explanation. Consider, for instance, the following definition.

\section{Definition of Causal Explanation:}

EXP is a causal explanation $=_{\text {df. }}$ there is an entity $\mathrm{x}$ and reference to $\mathrm{x}$ in EXP is an appropriate means to explain why a certain effect has occurred. 
If one assumes this definition is correct, it will quickly become clear how an action associated with date and time can be explained on the moderate reading. This becomes particularly clear if one fortifies the sub-condition $[(\mathrm{P} 1 *$ (iii) $]$ of the explanatory argument in the following manner: not only the total cause $\mathrm{C}$, but every essential part of $\mathrm{C}$ must be able to explain why E occurs at time t. Accordingly, one can now object: If the agent himself is supposed to be an essential part of the total cause of his action, then this part must be able to explain why the action has occurred at t. This is apparently not possible in the framework of the moderate reading.

Randolph Clark (2003) - who is known as the main proponent of the event-integrated approach ${ }^{7}$ - has directly reacted to this accusation. He differentiates two perspectives under which the highlighting of causes are of interest to us. While the reference to events aims to explain the effects that have actually occurred, this is not the case with the causal mention of agents - understood as substantial particulars. The latter fulfills the purpose of answering the question of why someone had the opportunity to make an active choice between various action alternatives. The reference to substances makes it clear that someone who wants to do something different as an alternative to the existing action must have the ability to intervene in the context of his intentions. Therefore, the above definition of the causal explanation is too narrowly stated. Since answers that are given to why-questions do not concern - at least not in the first instance - genuine causal explanations; they are related to the agent's ability to control which of the different action and decision alternatives determine his actual behavior. Thus, considerations that concern the exercise of active control are not aimed at causal explanations in the real sense. And if one accepts that within the framework of the event-integrated approach the agent is not cited for the sake of a causal argument, then the difficulties associated with it do not represent a serious problem. ${ }^{8}$

Certainly, it can barely be disputed that why-questions exhibit various aspects, especially natural pragmatic ones. Nonetheless, I still believe that Clark's rescue attempt is not ultimately convincing. Essentially, I have three basic doubts. First of all, the following objections can be raised from the external perspective. When an agent produces an event caused by an action this does not happen because the agent himself creates a certain event- at least not according to the moderate viewpoint. The real reason is

${ }^{7}$ Compare: Alvarez \& Hyman (1998).

${ }^{8}$ See Clarke $(2003,200)$. 
that the production of his action has the property of being a co-determined event that occurs at a specific point in time. Substantial particulars can bring about action-initiated events associated with date and time only indirectly. This means that the date and time of the effect is not of the type that is brought about simply by the substantial particular. ${ }^{9}$ It is not the production of the being of a substance, but the event of 'having' a complex property that is temporally determined as the cause. However, in this case, it is impossible for a proponent of the moderate reading to claim that the mentioned explanatory argument does not represent a difficult problem.

Secondly, one must remember that until now agent causation has been championed by those who hold incompatibilist theories of free will. An agent only performs a free action - which is a prerequisite to being responsible for an action - when the causal factors that have led to the action are under his control. This control is at best guaranteed by the fact that the agent himself is the only originator of his action. With this background it is helpful to make it clear what goes against a compatibilist view of the theory of agent causation. For instance, let us take the following suggestion:

\section{The Compatibilist Version of Agent Causation: ${ }^{10}$}

The action $\mathrm{H}$ of the agent $\mathrm{S}$ is free (in terms of morally responsible) if and only if (i) $\mathrm{H}$ is caused, and (ii) the cause of $\mathrm{H}$ is $\mathrm{S}$.

This suggestion appears to be inadequate regarding the sole authorship criterion. It only says that $\mathrm{S}$ is the cause of $\mathrm{H}$, but does not rule out that there may be external factors that have made it necessary for $\mathrm{S}$ to bring about $\mathrm{H}$. Thus, complete causal control by the agent appears to be ruled out.

Are we justified in extending this skepticism also to the moderate reading? Certainly not. Since, according to this point of view, the traditional assumption of a linear causation must be rejected, if one assumes the principle of co-determination, then it is certainly conceivable that there are causes which are beyond the control of S. But this does not lead to the conclusion that $\mathrm{S}$ has not performed the action $\mathrm{H}$ freely. This is so since in addition to the event associated with date and time of 'having' certain reasons and intentions (that can be determined by external factors) there is at least one other cause that is within the active control of $\mathrm{S}$. But perceived in this manner, the moderate version of agent causation would be compatible with

\footnotetext{
${ }^{9}$ For discussion on this point, see O'Connor $(2002,353)$.

${ }^{10}$ See Markosian $(1999,268)$.
} 
a broad conception of determinism; since under the last stated aspect $\mathrm{H}$ can be brought about by $\mathrm{S}$ even though there are other deterministic causes which are beyond $\mathrm{S}$, but have influenced the bringing about of $\mathrm{H}$ as a codetermined total event.

Regardless of how one finally evaluates the compatibilist approach, it makes at least one point clear: based on the revisionist causal understanding, which forms the basis of the moderate reading, it seems to be impossible within the framework of this approach to protect the libertarian intuitions that are normally linked with the concept of agent causation.

This suspicion can be fortified in two respects. Proponents of the moderate reading assume, as seen, that the performance of a free action is a complex co-determined event. It then remains unclear how the libertarian notion that the agent is the cause and last source of his action, fits in with the claim that the agent's intentions and reasons only have causal relevance associated with date and time because there is an integrated event - the 'having' of reasons or intentions at $\mathrm{t}$ - whose causation did not originate from the agent. It thus stands to reason that there could be reasons or intentions of agent causation that explain the occurrence of his action, regardless of whether we comprehend the occurrence of these reasons as a part of the particular action that was initiated by the agent himself. But how can something contribute to the willful characterization of a person's action when the person himself does not have any influence over it? When the manner in which reasons determine actions are excluded from the active control of the agent - so that the agent at no time has any influence on them that can be considered as explanations for his action - it is not clear at all how the event that should explain the performance of his action is itself linked with the performance of the action itself. ${ }^{11}$

Moreover, it must be considered that the philosophical problem of free will is derived from a basic intuition, that freedom is a necessary prerequisite for moral responsibility. In this connection it can be shown that an incompatibilist approach can only promise results when it is able to represent the condition of the authorship and the principle of alternative possibilities together. ${ }^{12}$ The latter principle is necessary at least for the appreciation of deontic judgments. The agent's ability to decide if he can be reprimanded for something or not depends on whether there are deontic alternatives that

\footnotetext{
${ }^{11}$ As O'Connor $(2002,353)$ has argued, this could lead to a causally shielded event $C^{*}$ that still lies before a co-deterministic total causation $\mathrm{E}$ that causally determines the total event.

${ }^{12}$ I have justified this position in detail in Schmechtig (2006b).
} 
are subject to the agent's unlimited control. But, this assumption need not be incorporated into a compatibilist theory. Therefore, the account of event-integrated agent causation runs the risk - because it overlooks the separation of both notions - not to be able to explain why the choice between deontic alternatives is a necessary prerequisite for the understanding of moral obligations. ${ }^{13}$

\section{Substance Causation and the Problem of Luck}

With this I have come to a third counter plea. The starting point is the question of whether an event-integrated reading has the appropriate means to invalidate the so-called luck objection. Traditionally it is assumed that libertarianism can be attacked from two directions. Not only must a strict determinism be declined. A purely accidental causation would also disagree with the libertarian concept of free action. Usually, the agent himself - and not an indeterminist event - is the originator of the action. But, is this assumption enough? Is the agent's control within the moderate reading strict enough to ban the hazard of bringing about an accidental action?

Let us pose the following comparison: in the actual world $\mathrm{W}$ the agent $\mathrm{S}$ decides at time $\mathrm{t}$ to execute the action $\mathrm{H}$. Furthermore, there is a possible world $\mathrm{W}^{*}$ in which the same natural laws apply and which with regard to past events is fully identical with the actual world $\mathrm{W}$ at time t. However, $\mathrm{S}$ in $\mathrm{W}^{*}$ decides against executing $\mathrm{H}$. Up to time $\mathrm{t}$ it is totally open whether $\mathrm{H}$ takes place or not. According to the luck objection the agent has no causal control over what he would decide at t. Even though it is his decision whether he will execute the action $\mathrm{H}$ in the actual situation or not, but this decision is arbitrary. In just the same manner he could have decided differently in the context of $\mathrm{W}^{*}$. The difference between his actual action in $\mathrm{W}$ and a possible action in $\mathrm{W}^{*}$ is based on purely random factors. ${ }^{14}$

Before one contemplates whether this objection is a sweeping one, two constraints must be imposed: First of all the argument does not indicate that the actual decision - which was made by S in W - happened at random. Similar to the representation of the explanatory argument, the decisive critical point is actually that the mere reference to an agent is too little. In order to arrive at a form of control, a more concrete understanding of the

\footnotetext{
${ }^{13}$ For a general discussion of this issue: Haji (2004, 145f.).

${ }^{14}$ Clark $(2003,412)$ has referred to the fact that with the help of the classical 'rollback argument' it can be argued in a similar form.
} 
control is required in which the contrast between a merely possible action and the actual causation of $\mathrm{H}$ appears to be justified deliberately. ${ }^{15}$

Secondly, a solution of the luck objection cannot simply end with the claim that the agent's person determines the performance of his actions. ${ }^{16}$ The speculation that the problem of luck only occurs where entities like events form the basis of an indeterminist causation must itself be justified. If one uses an event-integrated approach for the justification, then one actually assumes that there is an additional entity at play in addition to the agent's causation. As seen, there is an event E - the 'having' of reasons or intentions by $\mathrm{S}$ - that co-determines the action $\mathrm{H}$. Accordingly, it can at least be claimed for the occurrence of this additional event that it is not under the control of S. And the general objection seems to be aimed at this.

In view of the last-named consideration one is inclined to defend the moderate reading of agent causation: Of course, events play an important role within the event-integrated explanation, but, in spite of this, the agent is a substance that finally performs the action. In contrast, however, Haji $(2004,140)$ has objected to this saying that the luck objection has two different aspects. The first aspect pertains to the fact that as a result of the fortuity of the decision, the agent himself disappears as a source of active control. ${ }^{17}$ The moderate reading, however, is not affected by this difficulty. This is because as long as the action $\mathrm{H}$ is co-determined by the agent qua substance, there will always be something whereby the actual causation in $\mathrm{W}$ differentiates itself from the event of a possible causation in $\mathrm{W}^{*}$. In contrast, the second aspect is that in spite of the agent's ability to intervene in the natural course of events at any time, there is a problem of extended control, i.e., the reference to the agent (whose ability for intervention) does not guarantee that the contrast between the actual and a possible execution of $\mathrm{H}$ has arisen on the basis of a non-accidental decision. The solution of the extended control aspect requires more than the claim that there was no fortuity because the agent always had the opportunity to intervene causally. What is missing is the fundamental explanation of why the nature of this control should not be subjected to the luck objection.

Is there a fundamental explanation? Along with Derk Pereboom (2006) I would say: 'Yes', there is one; but its price is too high. The aimed expla-

\footnotetext{
${ }^{15}$ In contrast, Clarke $(2005,215 f$.) has represented the view that notions of causal control within the framework of the event-integrated approach do not depend on a debate about contrasting explanations.

${ }^{16}$ See, e.g., Ginet (1997), Haji (2004), Mele (2005).

${ }^{17}$ Compare the aspect of the disappearing agent in Kane (1996) and Pereboom (2006).
} 
nation happens to lead back to the problem of temporal causation. As Peerboom makes clear, a solution to the luck objection is possible if an agent's reification is understood in such a manner that his causal force is not a component of the caused (complex) event. According to this, the agent has causal strength exclusively on the basis of his being a substance. Two characteristics are typical for this fundamental role of substance: (i) the agent is the cause of his decisions without himself being causally determined in a similar manner; (ii) there is a type of causal control that is behind every event causation, whereby the presence of such a control decides if the agent is morally responsible for his conduct.

This explanation is fundamental, since here the original assumption of a co-deterministic causation - which is indispensable for the event-integrated approach - is dispensed with. It appears that the luck objection can be averted only for this reason. Apparently the aspect of extended control concerns an understanding of causation for which it is not significant as to what takes place at which time. What is decisive is solely that the agent has the ability as a substance to do something that corresponds to his advance choice. However, this point of view has the consequence that the assumed substance causation must not only be able to be determined indirectly - as substances that are constitutive components of events - but also to have an independent ontological status. Moreover, with respect to the question of extended control, it seems to assume the following concept of agent causation: ${ }^{18}$

\section{Agent's Causal Definition of Event-Causation:}

An event $C$ causes another event $E$ if and only if there is a free agent $S$, and the bringing about the occurrence of an event $\mathrm{C}$ is an appropriate means for $\mathrm{S}$ to bring about the occurrence of an event E. ${ }^{19}$

Regarding this reductionistic approach, different objections can be raised. ${ }^{20}$ At this juncture I am not interested if such objections are justified. It is im-

\footnotetext{
${ }^{18}$ There are some proponents of agent causation, which based upon this or a very similar definition have represented the approach that the acting agent should be granted not only an epistemological, but also an 'ontological priority'. In this connection it is assumed that agent causation is not limited to the intentional actions of natural (living) substances. All persisting objects (living or non-living) therefore have a causal force. See, e.g., Lowe (2002, 195f. and 208ff.).

${ }^{19}$ A very similar formulation can be found with Menzies \& Price $(1993,187)$.

${ }^{20}$ See, e.g., Hausmann (1998), Keil (2000), Woodward (2003).
} 
portant if the mentioned definition of event causation fits in with the standard objection discussed in the introduction (explanatory argument). My thesis is that the approach of agent causation concerning this question confronts a fundamental dilemma: either one tries to solve the problem of the association with date and time by extending the process of agent causation to include a co-determined event, with the result that there is a part of the total cause that can be associated with date and time, in which case this solution has the big problem that due to the integrated event causation it is subject to the luck objection; or one tries to cancel the luck objection by neutralizing the problem with the conception of a substantial agent causation. However, with this procedure - even if it is convincing - one ends up again with the first problem. Once again it cannot be explained why reference to the agent is a contrastive explanation. Based upon the reductionistic treatment of event causation, it is impossible to separate the actual situation - in which the causation by $\mathrm{H}$ actually happened - from those cases in which nothing was done even though the agent with the same ability had already previously existed. If one combines both lines of argument then one can formulate the following objection:

\section{The Dilemma Argument:}

(A1) An adequate explanation of free will should be able to invalidate both the luck objection as well as the problem of temporal causation.

(A2) The luck objection is only avoidable within the framework of agent causation when there is a substantial explanation of the agent's extended control.

(A3) The problem of temporal causation is only avoidable within the framework of agent causation when the agent's causation contains a co-deterministic event.

(A4) A substantial explanation of extended control presumes a reductionistic approach of event causes.

(A5) An explanation of temporal causation presumes that events are a necessary component of agent causation.

(A6) The assumptions (A4) and (A5) are incompatible.

Based on (A1) the following is applicable:

(K) The approach of the agent causation does not furnish an adequate explanation of free will. 
At last it becomes clear with this argument that an event-integrated justification of agent causation leads to a dead end. Therefore, in the remaining section I will pursue a different path. The basis of my approach is the conviction that it is not the original concept of agent causation that requires a fundamental revision in the context of the 'double causation'; far more - in order to avoid the mentioned dilemma - modification must be made at another location.

\section{Four-Dimensional Agent Causation}

If one compares the different approaches to agent causation, it becomes noticeable that there is a large agreement in one point:

"All AC [agent-causal] theorists required that we think of agents as thinkers which endure through time, such that they are wholly present at each moment of their existence."(O’Connor 2002, 341 - emphasized P.Sch.)

In contrast to this I would like to represent the view that the cited dilemma argument is most easily rebuffed when one dismisses this basic assumption. The solution to the luck objection collides with the problem of temporal causation not because of the agent-related causal concept, but because of the fact that the temporal existence of substantial particulars is understood in the traditional Endurance-Persistence Model (EPM for short). ${ }^{21}$ Only under this determination is one compelled to introduce an event entity in addition to agent causation, whereas we have seen that such an extension of the agent concept represents the actual problem.

Why do proponents of agent causation believe that their approach is only justified when the traditional (EPM) is true? I think it is the specific interconnection of two assumptions that play a decisive role here: (i) substances are viewed as continuants, with which the separation between the occurrence at the present moment and the constituted being in a fourdimensional sequence (of temporal parts) does not seem to make sense. Events exhibit a hybrid existence status with respect to type and the man-

${ }^{21}$ Usually one differentiates between two rival approaches of the persistence explanation. The traditional Endurance-Persistence Model (EPM) says: an object O persists ${ }_{\text {df. }} \mathrm{O}$ is entirely present at more than only one point of time. On the other hand, the definition of the Perdurance-Persistence Model (PPM) is: an object O persists $=_{\mathrm{df}} \mathrm{O}$ has temporal parts and none of these parts is completely present at more than one point of time. 
ner in which they occur chronologically, while the opposite is claimed of substantial particulars. ${ }^{22}$ Continuants do not have genuine temporal parts since they are entirely in the present throughout their existence. Thus it is impossible for there to be an earlier temporal component of the continuant that did not bring about the actual causal event since it has already elapsed at the time of the present causation. (ii) Secondly, one assumes that there is a necessary connection between the manner in which the object's persistence must be explained and the general idea of temporal existence that can be inferred from it. While the traditional (EPM) is supposed to be inevitably connected with a three-dimensional present tense time concept, the counter position demands - the Perdurance-Persistence Model (PPM in short) - a four-dimensional eternal view. And since both time conceptions are mutually exclusive, one perceives endurance-objects that exist in a four-dimensional space to be unthinkable.

If one considers both assumptions together, then the impression is given of agents who continuously have a causal ability so that one is inevitably fixed to a three-dimensional present time conception. It is because of this conception that the problem of temporal causation represents a risk for the approach of agent causation. In view of this, the question arises as to why continuants should not be taken to have temporal parts and in a fourdimensional space. The advantage of (PPM) is obvious. Insofar as substances have temporal parts, a rebuttal of the explanatory argument is easy to contemplate: even though the agent exists continuously in time, e.g., in the interval from $t_{1}$ to $t_{3}$, there are different temporal parts that explain why the action $\mathrm{H}$ occurred at $\mathrm{t}_{3}$ and not at $\mathrm{t}_{1}$. However, from the agent's causal point of view, (PPM) requires that which continuously exists to be the total of all temporal parts (space-time-worm). In contrast to this, that which actually performs the action at a certain time is always only a temporal part of this totality. ${ }^{23}$ It is then certainly not the causal ability of the temporal

\footnotetext{
22 Therefore, the view is often represented that causal effects can only be produced by such entities which in a specific way exist in the time period. Events could take place within a temporal interval even though they have genuine parts which at this time period have already happened and do not belong to the present occurrence of the events. Obviously events are better suited to explain the temporal occurrence of a cause. One can say about an event that its occurrence at an earlier time period was the cause for a certain effect, even though the same event is presently occurring and does not produce this effect. In contrast by substantial individual entities which are totally present at all times this seems to be possible. Compare the hybrid temporal existence status of events: Lombard (1999, 256ff.), Schmechtig (2006, 100ff.).

${ }^{23}$ For discussion on this point, see O'Connor $(2002,341)$.
} 
part that continues to exist. So how can the causal ability that is only available with the totality of all temporal parts provide an explanation for something caused at a specific point of time? Such ability would also still exist when the particular temporal part, which represents a concrete causation, is already in the past. But, of course, this means that a contrasting explanation would be impossible.

In addition it would be implausible to claim that it is not the agent simpliciter, but merely a temporal part of him that performs an action. Just what does it mean to be an instant part of the agent? We normally speak in the case of natural substances only of temporal parts as states of the same object that have occurred in previous or subsequent phases of its life. However, the state associated with a specific phase of its life is not an independent continuant, which continues to exist in time in spite of changes. And a reification in the context of the (PPM), that the quantity of all instantaneous states is that which actually persists, also does not help. This is because under this claim the following adequacy condition (the explanation of persistence) would be violated: something can only be called a persistent object -continuously existing despite changes - when it itself is the object of the change, i.e., the concerned object is the carrier of those properties which themselves change. ${ }^{24}$

Admittedly, objections of this type have a certain justification. Still, from this does it follow that there is no alternative to the traditional (EPM)? I don't think so. This is because it is principally wrong to assume that a necessary linkage must exist between the persistence of substantial particulars and a three dimensional time approach. If one rejects this incorrect linkage thesis, ${ }^{25}$ then we are free to determine the agent's temporal existence on the basis of external relations to predecessor's and successor's phases. According to this the agent does not persist because there was a previous state that exists at the present point of time in exactly this previous state, but instead because previous or subsequent states of the agent are predecessor or successor phases that are constituted together in a fourdimensional space. And even though the presently occurring agent is linked via external relations to such predecessor and successor phases, they do not represent independent temporal parts of a spatiotemporal whole. Instead, the phases must themselves be understood as autonomous substantial particulars. Their distinctiveness lies therein, that on the one hand - at time of their present occurrence - they are perceived as three dimensional enti-

\footnotetext{
${ }^{24}$ For this suggestion, see Haslanger ( 2003, 331ff.).

${ }^{25}$ Compare to a detailed justification of this claim: Schmechtig (2006a).
} 
ties; but on the other hand, beyond the present point of time - within a four-dimensional space - they are constituted with other predecessor and successor phases (linked by means of external relations). If one views the agent's continuous existence under the prerequisite of a two-dimensional time approach $^{26}$ the adequacy condition just discussed remains intact because substantial particulars whose persistence is explained in this manner have causal ability simpliciter; and of course are themselves - as carriers of the respective properties - the proper subject of changes.

In view of the fact that the suggested modification contains elements of both persistence models, it is appropriate to speak of an independent (third) explanatory approach.

\section{The Exdurance-Persistence Model: ${ }^{27}$}

An agent $\mathrm{S}$ persists $=_{\text {df. }}$ (i) $\mathrm{S}$ is a three dimensional substantial individual entity; and (ii) the present occurrence of $S$ is linked with different predecessor and successor phases in virtue of external relations; and (iii) the temporal existence of $\mathrm{S}$ includes all predecessors and successors with which $\mathrm{S}$ is constituted in a four-dimensional space.

Since the model is based on a two-dimensional time concept it is easy to see how the cited dilemma argument can be circumvented. In a manner similar to the above example, an agent $S$ - who continuously exists throughout a temporal interval from $t_{1}$ to $t_{3}$ - causes the action $H$ in the present at time $t_{3}$. Even though $S$ is entirely present at $t_{1}$, there are various predecessor phases with which $S$ is linked in a common four-dimensional space. The independence of these phases explains why $\mathrm{H}$ has not been caused either at $t_{1}$ or $t_{2}$. In order to create the explanatory contrast sought, it is not necessary to introduce an additional event. It is enough to know that there are predecessor phases, which, on the one hand are linked with $\mathrm{S}-$

\footnotetext{
${ }^{26}$ The discussion concerns a two dimensional time conception, because the agent's appearance in the present according to an A-sequence of time is understood as being in the present, whereas, in contrast the continuing existence (persistence) has to be perceived in the form of a hybrid connection that exists between the agent's appearance in the present time and his constituted being in a four-dimensional sequence of the predecessor and successor phases (B-sequence).

27 The concept of Exdurance originates from a suggestion by Sally Haslanger (2003, 319). In comparison to her concept I assume that objects which persist in the context of the Exdurance theory are no 'perduring particulars', but are only represented by the usual ordinary three-dimensional objects.
} 
according to the common constitution in four-dimensional space; but which, on the other hand - what concerns the ontological status of the present causation by $\mathrm{H}$ - are drastically differentiated from $\mathrm{S}$. This is because at $t_{3}$, the actual cause of $\mathrm{H}$ is of course, only $\mathrm{S}$, but no predecessor or successor phases of the present $\mathrm{S}$.

If one considers the agent's temporal existence within the framework of the Exdurance-Persistence Model then premise (A3) of the cited dilemma argument must be dismissed. Thus, the agent's approach is no longer subject to the luck objection. And if at the same time a co-deterministic event causation is dispensed with, then the objection of the contrasting explanation can also be invalidated. In other words, if one revises the predominant view that the continued temporal existence of agents is linked to the traditional (EPM), the whole objection falls apart. Whether it is possible to maintain that an agent's causality is the only form of causality is an independent question. One is, in any case, not bound to a reductionistic view with the proposed solution. One need only retain the idea that there are continuants whose temporal existence - in virtue of constitutive relations is anchored to different predecessor and successor phases in a fourdimensional space.

\section{REFERENCES}

Alvarez, M. / Hyman, J. 1998 “Agents and their Action”, Philosophy, 73, 219-239.

Aune, B. 1977 Reason and Action, Dordrecht: Reidel.

Broad, C.D. 1952 "Determinism, Indeterminism, and Libertarianism”, Ethics und History of Philosophy: Selected Essays, New-York: Humanities Press, 195-217.

Chisholm, R. 1985 „Freiheit und Handeln“, in G. Meggle (Hrsg.), Analytische Handlungstheorien, Frankfurt a. M.: Suhrkamp, 354-387.

- 1995 “Agents, Causes, and Events: The Problem of Free Will”, in T. O'Connor (ed.), Agents, Causes, Events - Essays on Indeterminism and Free Will, Oxford: University Press, 95-100.

Clarke, R. 1996 "Agent Causation and Event Causation in the Production of Free Will", Philosophical Topics, 24, 19-48.

- 2003 Libertarian Accounts of Free Will, Oxford: University Press.

- 2005 'Agent Causation and the Problem of Luck', Pacific Philosophical Quarterly, 86, 408-421.

Ehring, D. 1997 Causation and Persistence, Oxford: University Press.

Ekstrom, L.W. 2000 Free Will: A Philosophical Study, Boulder, Co.: Westview.

Ginet, C. 1990 On Action, Cambridge: University Press.

Haji, I. 2004 “Active Control, Agent-Causation and free Action”, Philosophical Explorations, 7, 131-148. 
Hausman, D. 1998 Causal Asymmetries, Cambridge: Cambridge University Press.

Lombard, B.L. 1999 "On the Alleged Incompatibility of Presentism and Temporal Parts", Philosophia, 27, 253-260.

Lowe, E.J. 2002 A Survey of Metaphysics, Oxford: University Press.

Markosian, N. 1999 'A Compatibilist Version of the Agent Causation', Pacific Philosophical Quarterly, 80, 25-277.

McCann, H. 1998 The Work of Agency: On Human Action, Will and Freedom, Ithaca: Cornell University Press.

Mele, A. 1995 Autonomous Agents: From Self-Control to Autonomy, Oxford: University Press.

Menzies, P. \& Price, H. 1993 "Causation as a Secondary Quality”, British Journal for the Philosophy of Science, 44, 187-203.

O’Connor, T. 1995 “Agent Causation”, in Agents, Causes, Events - Essays on Indeterminism and Free Will, Oxford: University Press, 173-200.

- 2000 Persons and Causes, Oxford: University Press.

- 2002 'Libertarian Views: Dualist and Agent-Causal Theories', in R. Kane (ed.), The Oxford Handbook of Free Will, Oxford: University Press, 337-355.

Pereboom, D. 2006 "Is Our Conception of Agent-Causation Coherent?", Philosophical Topics.

Schmechtig, P. 2006a „Zeit und Persistenz“, Metaphysica, 7 (1), 87-121.

- 2006b ,'Flicker of Freedom' und moralische Verantwortung - Eine deontische Verteidigung des Prinzips der alternativen Möglichkeiten“, Dresden Preprints in Theoretical Philosophy and Philosophical Logic, 25.

Taylor, R. 1966 Action and Purpose, Englewood Cliffs, New-York.

van Inwagen, P. 2002 "Free Will Remains a Mystery", in R. Kane (ed.), The Oxford Handbook of Free Will, Oxford: University Press, 158-177.

von Wachter, D. 2003 "Free Agents as Cause", in K. Petrus (ed.), On Human Persons, Frankfurt a.M. / London: Ontos, 183-194.

Woodward, J. 2003 Making Things Happen: A Theory of Causal Explanation, Oxford: University Press. 
